\title{
On the force of $\mathrm{V} 2$ declaratives*
}

\author{
Hans-Martin Gärtner (ZAS Berlin) \\ gaertner@zas.gwz-berlin.de
}

\begin{abstract}
:
This paper discusses a variant of German V2 declaratives sharing properties with both subordinate relative clauses and main clauses. I argue that modal subordination failure helps decide between two rivaling accounts for this construction. Thus, a hypotactic analysis involving syntactic variable sharing must be preferred over parataxis plus anaphora resolution. The scopal behavior of the construction will be derived from its 'proto-assertional force,' which it shares with similar 'embedded root' constructions.
\end{abstract}

It is well-known that the syntactic position of finite verbs in German is sensitive to the main vs. subordinate clause distinction. V1 and V2 structures tend to be main clauses while V-final order usually indicates subordination. However, exceptions in both directions have repeatedly been reported and even studied in more or less detail (cf. Reis 1997 and references cited there.) Here I would like to further our understanding of 'embedded V2' declarative clauses by investigating the following question.

(1) Q1: Are there V2 relative clauses in German?

I suggest that a proper answer to Q1 requires close analysis of minimal triples like the following. (Finite verbs are underlined in the relevant clauses.)

(2) a. Das Blatt hat eine Seite (/), die ganz schwarz ist. the sheet has one side that entirely black is 'That sheet of paper has one side that is entirely black'

b. Das Blatt hat eine Seite (/), die ist ganz schwarz.

c. \#Das Blatt hat eine Seite ( $)$. Die ist ganz schwarz.

While (2a) involves a standard V-final relative clause and (2c) displays the sequence of two independent main clauses, the status of $(2 \mathrm{~b})$ is unclear. This will be reflected in the following terminological convention.

(3) Terminological Convention

a. $\quad$ Call the second clause in (2b) 'V2 Relative' (V2R) if you want to emphasize properties it shares with its counterpart in (2a).

For comments and suggestions, I would like to thank the participants of the workshop on 'Informationsstruktur und der referentielle Status von sprachlichen Ausdrücken' at the DGfS meeting in Leipzig (2001) and the one on 'The Roots of Pragmasemantics II' in Szklarska Poreba (2001).

The paper is submitted to a special issue of 'Theoretical Linguistics', edited by Klaus von Heusinger and Kerstin Schwabe 
b. Call the second clause in (2b) 'Integrated Verb Second' (IV2) if you want to emphasize properties it shares with its counterpart in $(2 \mathrm{c})$.

Remaining neutral at this stage, I will conflate the two terms in (3) and refer to the sentence type at issue as 'V2R/IV2.'

To begin with, the following three properties of V2R/IV2 should be noted.

\section{(Curious) Properties of V2R/IV2}

a. V2R/IV2 has to be immediately preceded by non-final phonological boundary marking (/).

b. $\quad$ V2R/IV2 can only modify indefinites in the putative matrix clause.

c. $\quad$ V2R/IV2 is able to restrictively modify its antecedent.

(4a) is important for distinguishing V2R/IV2 from parenthetical counterparts, for which most of the generalizations discussed here do not hold. The issue of quantifiers compatible with V2R/IV2 indicated in (4b) will not be taken up in this paper, although one way to account for it may be inferable from the analysis presented below.' $(4 \mathrm{c}) \mathrm{can}$ be substantiated by the observation that the initial clause in $(2 \mathrm{c})$ triggers the Horn-scale implicature (5).

(5) The sheet of paper has no more than one side

(5) arises in order to restore informativity to an otherwise vacuous sentence, given world knowledge such as is expressed in (6).

$$
\forall \mathrm{x}[\text { Sheet of Paper }(\mathrm{x}) \rightarrow \exists \mathrm{Y}[\mathrm{Y}=\{\mathrm{z} \mid \text { Side of }(\mathrm{z}, \mathrm{x})\} \wedge|\mathrm{Y}|=2]]
$$

The inconsistency of (5) and (6) then resuit in pragmatic anomaly (\#). Crucially, implicature (5) does not arise with (2a) or $(2 b)$. This is evidence that there the initial clause is not evaluated in isolation. Instead the indefinite description is semantically intersected with the content of the adjacent clausal modifier, i.e. it is restrictively modified.

Another curious property of V2R/IV2 concerns scope.

(4) d. V2R/IV2 forces its indefinite antecedent to take wide scope.

Thus, consider (7).

(7) a. Maria möchte einen Fisch fangen $(/)$, der kariert ist. Maria wants a fish catch that checkered is 'Mary wants to catch a fish that is checkered'

b. Maria möchte einen Fisch fangen (/), der ist kariert.

c. Maria möchte einen Fisch fangen ( $)$. Der ist kariert.

Here only (7a) is neutral as for the scope of the indefinite. (7b) and (7c), on the other hand, invariably induce a de re reading. In order to account for that effect, we may assimilate $(7 \mathrm{~b})$ to $(7 \mathrm{c})$ on the basis of $(8)$.

i For detailed discussion and an account based on different premises, see Gärtner (1998, forthcoming). 


$$
\begin{aligned}
& \text { Paratactic Hypothesis }(\mathrm{PH})^{2} \\
& \text { V2R/IV2 is a case of parataxis. }
\end{aligned}
$$

This could be fleshed out syntactically by postulating the existence of a functional category $\pi_{R E L}$, which takes V2R/IV2 as its complement and another clause containing an indefinite as its specifier. (9) illustrates that idea.

$$
\left[\pi \mathrm{P}[\mathrm{CP} 1 \ldots]\left[\pi^{\prime} \pi_{\mathrm{REL}}[\mathrm{CP} 2=\mathrm{V} 2 \mathrm{R} / \mathrm{IV} 2 \ldots]\right]\right]
$$

$\mathrm{PH}$ predicts that V2R/IV2 involves anaphora resolution like (7c), that process being subject to standard conditions on accessibility. Therefore, (7b) would require a de re reading of the indefinite.

A closer look at pronouns linking the two clauses provides a fairly subtle additional argument in favor of PH and the concomitant anaphora-resolution view of V2R/IV2. (2) has already shown that all three constructions tolerate weak demonstratives. (10) adds $w$-pronouns and personal pronouns, none of which can figure in V2R/IV2.

(10) a. Das Blatt hat eine Seite (/), welche ganz schwarz ist.

b. $\quad *$ Das Blatt hat eine Seite (/), sie ganz schwarz ist.

c. $\quad *$ Das Blatt hat eine Seite $(/)$, welche ist ganz schwarz.

d. $\quad *$ Das Blatt hat eine Seite (/), sie ist ganz schwarz.

e. $\quad *$ Das Blatt hat eine Seite (l). Welche ist ganz schwarz.

f. \#Das Blatt hat eine Seite (1). Sie ist ganz schwarz.

This is summarized in (11) ( $w d=$ weak demonstrative; $w=w$-pronoun; pers $=$ personal pronoun).

(11) Pronoun Compatibility
a. Standard Relative Clauses:
b. V2R/IV2:
$[+w d] /[+w] /[-$ pers $]$
c. Cross-sentential anaphora:
$[+w d] /[-w] /[-$ pers $]$
$[+w d] /[-w] /[+$ pers $]$

The following paradigm, again in the domain of weak demonstratives, provides the crucial contrast.

(12) a. *Es gibt Länder (/), da das Bier ein Vermögen kostet.

It gives countries there the beer a fortune costs

b. Es gibt Länder (/), da kostet das Bier ein Vermögen.

c. \#Es gibt Länder ( $)$. Da kostet das Bier ein Vermögen.

While most weak demonstratives are (homonyms of) relative pronouns, the pronoun $d a$ ('there') is not. It can be used in contexts of cross-sentential anaphora but is banned from V-final relative clauses. Its compatibility with V2R/IV2 (12b) indicates that this construction patterns with cross-sentential anaphora.

However, the picture just outlined must be further complicated in the light of the following question.

2 See Gärtner (1998, forthcoming) for a comprehensive version of PH, including independent empirical evidence and a DRS-update mechanism able to cope with (most of) the scope facts. 
Curiously, this prediction underlying $\mathrm{PH} / \mathrm{Q} 2$ is not borne out, as (14) demonstrates.

(14) a. Maria möchte einen Fisch fangen (/), den sie essen könnte. Mariawant a fish catch that she eat could 'Mary wants to catch a fish that she could eat'

b. *Maria möchte einen Fisch fangen (/), den könnte sie essen.

c. Maria möchte einen Fisch fangen ( ). Den könnte sie essen.

Note, however, that property (4a) makes one suspect that V2R/IV2 does not give rise to text formation the way a sequence of sentences does. In fact, integration into the preceding clause is obligatory, given property $(4 \mathrm{e})$.

e. V2R/IV2 forms an 'information unit,' definable as a single partition into focus and background, with its putative matrix clause.

(4e) is one of the essential building blocks in developing a formal account for the facts in (14). Thus, according to Groenendijk\&Stokhof (1989) (cf. Honcoop 1998, Sæbø 1999), modal subordination involves a propositional discourse referent provided by an antecedent clause and picked up by a covert anaphor in the restrictor of a modal operator in the follow-up clause. ${ }^{3}$ Given (4e), however, V2R/IV2 is itself part of the minimal proposition able to provide the required discourse referent. That is, V2R/IV2 is evaluated before the required discourse referent may become available. Therefore, modal subordination must fail and unacceptability of (14b) is predicted. ${ }^{4}$

Unfortunately, this way of dealing with (14b) runs into additional problems with $\mathrm{PH}$. Q3 formulates the relevant issue.

(15) Q3: Doesn't PH rely on the mechanism of anaphora resolution and thus evaluation of V2R/IV2 after evaluation of the putative matrix clause?

Clearly, in order to avoid contradiction I must revise $\mathrm{PH}$. I suggest that $\mathrm{PH}$ be replaced by $(16) .^{5}$

3 Concretely, Groenendijk\&Stokhof (1989:38ff) argue that (i) should be given the meaning in (ii).

(i) Ein Tiger könnte hereinkommen (1). Der würde dich zuerst fressen.

(ii) Possibly (a tiger comes in) and necessarily (if a tiger comes in, it eats you first)

Technically this is implemented as in (iii).

(iii) a. would $\psi=\lambda p\left[\quad\left[{ }^{\vee} D_{<s,<<s,(>, \infty)} \Rightarrow \psi\right] \wedge \wedge^{\vee} \mathrm{p}\right]$

b. possibly $\phi=£ D \lambda p\left[\diamond \downarrow{ }^{\vee} \mathrm{D} \wedge \wedge^{\vee} \mathrm{p}\right](\phi)$

'by dynamic conjunction' + 'some plausible assumptions about the semantics of this extension of DIL' + 'some obvious reductions':

c. $\lambda p[\diamond \downarrow \phi \wedge \quad \downarrow[\phi \Rightarrow \psi] \wedge \vee p]$

Crucially, the indefinite in $\phi$ becomes accessible for dynamic binding of a pronoun in $\psi$, within the scope of .

4 As far as I can see, this account carries over to the presuppositional theory of modal subordination developed in Geurts (1999).

5 This move will leave the above mentioned pronoun facts without a satisfactory account. 
(16) Hypotactic Hypothesis ( $\mathrm{HH})$

V2R/IV2 is a case of standard (relative clause) hypotaxis.

Under HH, V2R/IV2 would share a variable with its indefinite antecedent, due to syntactic copying. Thus, the issue of anaphora resolution does not arise. Of course, $\mathrm{HH}$ generates the follow-up question in (17).

(17) Q4: How can V2R/IV2 and standard relative clauses be distinguished on the basis of $\mathrm{HH}$ ?

The answer to Q4 lies in property (4f), the final one discussed in this paper.

(4) f. V2R/IV2 is an instance of 'embedded root phenomena' (a.k.a. 'dependent main clause phenomena').

Building on earlier work in this area (cf. Hooper\&Thompson 1973, Wechsler 1991, Reis 1997), I would like to defend the following hypothesis.

Proto-Force Hypothesis (PFH)

$\mathrm{V} 2$ declaratives have proto-assertional force.

Proto-assertional force forces V2R/IV2 together with its indefinite antecedent out of the scope of modal operators and negation (among many others). Interaction with negation is documented in (19).

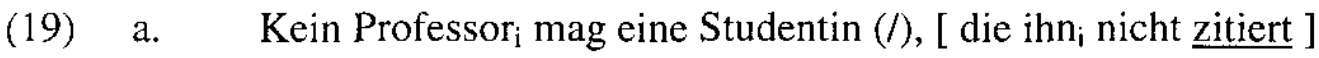
No professor likes a female student who him not cites 'No professor likes a female student that doesn't cite him'

b. *Kein Professor mag eine Studentin (/), [ die zitiert ihn $_{\mathrm{i}}$ nicht ]

Since the negative quantifier in (19) binds the personal pronoun, the modifying clause is forced into the scope of negation. This fails in the case of V2R/IV2.

My claim then is that combining $\mathrm{HH}$ and $\mathrm{PFH}$ properly treats the properties of V2R/IV2. HH prevents modal subordination, which accounts for the unacceptability of (14b). PFH prevents syntactic 'scopal subordination.' This predicts the unacceptability of (14b) and (19b), as well as the unavailability of a de dicto reading in (7b).

At this stage, I cannot present a formal theory underlying PFH. Yet, a number of adequacy criteria indicative of the structure of such a theory are fairly clear. Thus, consider (20).

(20) Adequacy Criterion for PFH

'Embedded Force Exclusion' should be met.

This well-known issue has recently been raised again by Green $(2000, \mathrm{p} .440)$.

(21) Embedded Force Exclusion (EFE)

If $\varphi$ is either a part of speech or a sentence, and $\varphi$ contains some indicator $f$ of illocutionary force, then $\varphi$ does not embed. 
Thus, it is preferable to avoid simplistic direct endowment of V2 declaratives with assertional force (potential). This requirement is met by PFH. Proto-forces will then have to be supplemented by (projection) rules of the following kind.

Proto-Assertional Force Construal

a. Unembedded proto-assertional force translates into assertional force (potential).

b. Embedded proto-assertional force can be 'absorbed' by assertional force (potential) if there is no intervener.

c. Embedded proto-assertional force can be 'absorbed' on arguments of predicates that denote acts of assertion etc.

d. Non-absorbed proto-assertional force leads to semantic/pragmatic deviance.

(22c) takes care of complementation by V2 clauses, the content of which is not a speaker assertion. An example is given in (23).

Ich hoffe du glaubst mir

I hope you believe me

The main theoretical burden of (22) rests on a notion of 'intervener,' which will have to be the subject of further research. ${ }^{6}$

In sum, I have argued that V2R/IV2 should be given a hypotactic analysis. Its scopal behavior, resulting in modal subordination failure, must be derived from its protoassertional force. Proto-force in turn should be linked to the embedded root nature of V2R/IV2. If such an analysis is on the right track it would also justify giving a positive answer to question Q1.

\section{References:}

Gärtner, Hans-Martin (1998): "Does German Have V2 Relative Clauses?" Sprache und Pragmatik 48.

Gärtner, Hans-Martin (forthcoming): "Are There V2 Relative Clauses in German?" Journal of Comparative Germanic Linguistics 3.3. Geurts, Bart (1999): Presuppositions and Pronouns. Oxford: Elsevier.

6 To the extent that material in the scope of a universal quantifier is not (directly) asserted, universal quantifiers may count as 'interveners.' It is therefore important to note that V2R/IV2 can - under certain conditions (see Gärtner 1998, forthcoming) - modify an indefinite in the scope of a universal quantifier. This is shown in (i).

(i) a. Jedes Haus hat ein Zimmer, [ in dem . ist es gemütlich ]

Every house has a room in that $t_{D A T}$ is it cosy

b. Jeder Bergi hat eine Flanke, [ über die lässt er ${ }_{i}$ sich leicht besteigen ]

Every mountain has a face over that ${ }_{A C C}$ lets it itself easily climb

'Every mountain has a face across which one can climb it easily.'

However, a functional interpretation of the indefinite as proposed by Groenendijk\&Stokhof (1984) would remove the content of V2R/IV2 from the scope of the universal quantifier every house, as indicated in (ii).

(ii) $\exists \mathrm{f}[\mathrm{R}(\mathrm{f}) \wedge \forall \mathrm{x} \cdot \operatorname{COSY}-\operatorname{ROOM}(\mathrm{f}(\mathrm{x})) \wedge \forall \mathrm{y}[\operatorname{HOUSE}(\mathrm{y}) \rightarrow \operatorname{HAVE}(\mathrm{y}, \mathrm{f}(\mathrm{y}))]]$ 
Green, Mitchell S. (2000): "Illocutionary Force and Semantic Content," Linguistics and Philosophy 23: 435-473

Groenendijk, Jeroen \& Martin Stokhof (1984): "Interrogative Quantifiers and Skolem functions," In Groenendijk,J.\&M.Stokhof, Studies on the Semantics of Questions and the Pragmatics of Answers, Ph.D. dissertation, University of Amsterdam. 165-208.

Groenendijk, Jeroen \& Martin Stokhof (1989): "Dynamic Montague Grammar," ITLI Prepublication Series X-89-04. University of Amsterdam.

Honcoop, Martin (1998): Dynamic Excursions on Weak Islands. The Hague: Holland Academic Graphics.

Hooper, Joan \& Sandra Thompson (1973) "On the Applicability of Root Transformations," Linguistic Inquiry 4: 465-497.

Reis, Marga (1997): "Zum syntaktischen Status unselbständiger Verbzweit Sätze," In D'Avis, F. \& U. Lutz (eds.), "Zur Satzstruktur des Deutschen," Arbeitspapiere des SFB $340 \mathrm{Nr}$. 90. Stuttgart and Tübingen. 121-142.

Sæbø, Kjell Johan (1999): "Discourse Linking and Discourse Subordination." in Bosch, P. \& R. van der Sandt (eds.), Focus. Cambridge: CUP. 322-335.

Wechsler, Stephen (1991): "Verb Second and Illocutionary Force." in Leffel, K. \& D. Bouchard (eds.), Views on Phrase Structure. Dordrecht: Kluwer. 177-191. 